\title{
When Is Carotid Angioplasty and Stenting the Cost-Effective Alternative for Revascularization of Symptomatic Carotid Stenosis? A Canadian Health System Perspective
}

\author{
M.A. Almekhlafi, M.D. Hill, S. Wiebe, M. Goyal, D. Yavin, J.H. Wong, and F.M. Clement
}

\begin{abstract}
BACKGROUND AND PURPOSE: Carotid revascularization procedures can be complicated by stroke. Additional disability adds to the already high costs of the procedure. To weigh the cost and benefit, we estimated the cost-utility of carotid angioplasty and stenting compared with carotid endarterectomy among patients with symptomatic carotid stenosis, with special emphasis on scenario analyses that would yield carotid angioplasty and stenting as the cost-effective alternative relative to carotid endarterectomy.
\end{abstract}

MATERIALS AND METHODS: A cost-utility analysis from the perspective of the health system payer was performed by using a Markov analytic model. Clinical estimates were based on a meta-analysis. The procedural costs were derived from a microcosting data base. The costs for hospitalization and rehabilitation of patients with stroke were based on a Canadian multicenter study. Utilities were based on a randomized controlled trial.

RESULTS: In the base case analysis, carotid angioplasty and stenting were more expensive (incremental cost of $\$ 6107)$ and had a lower utility ( -0.12 quality-adjusted life years) than carotid endarterectomy. The results are sensitive to changes in the risk of clinical events and the relative risk of death and stroke. Carotid angioplasty and stenting were more economically attractive among high-risk surgical patients. For carotid angioplasty and stenting to become the preferred option, their costs would need to fall from more than $\$ 7300$ to $\$ 4350$ or less and the risks of the periprocedural and annual minor strokes would have to be equivalent to that of carotid endarterectomy.

CONCLUSIONS: In the base case analysis, carotid angioplasty and stenting were associated with higher costs and lower utility compared with carotid endarterectomy for patients with symptomatic carotid stenosis. Carotid angioplasty and stenting were cost-effective for patients with high surgical risk.

ABBREVIATIONS: $B$ URST = Burden of Ischemic Stroke; $\mathrm{CAS}=$ carotid angioplasty and stenting; $\mathrm{CEA}=$ carotid endarterectomy; $\mathrm{CREST}=$ Carotid Revascularization Endarterectomy versus Stenting Trial; EVA-3S = Endarterectomy versus Angioplasty in Patients with Symptomatic Severe Carotid Stenosis; $\mathrm{Ml}=$ myocardial infarction; QALY = quality-adjusted life years; SAPPHIRE = Stenting and Angioplasty with Protection in Patients at High Risk for Endarterectomy

$\mathbf{S}$ troke is a costly illness. Stroke prevention among patients with symptomatic carotid stenosis requires carotid revascularization. This can be done surgically as carotid endarterectomy $(\mathrm{CEA})^{1}$ or less invasively through carotid angioplasty and stent placement (CAS). ${ }^{2}$ Both are used in combination with optimal medical therapy. Approximately 5000 CEA procedures were per-

Received April 19, 2013; accepted after revision May 29.

From the Departments of Clinical Neurosciences (M.A.A., M.D.H., S.W., M.G., D.Y., J.H.W.), Medicine (M.D.H.), Community Health Sciences (M.D.H., S.W., F.M.C.), and Radiology (M.G., M.D.H.), Hotchkiss Brain Institute, University of Calgary, Calgary, Alberta, Canada; and Department of Internal Medicine (M.A.A.), King Abdulaziz University, Jeddah, Saudi Arabia.

Please address correspondence to Mohammed A. Almekhlafi, MD, MSc, FRCP(C) Foothills Medical Center, 1403 29th St NW, Calgary, Alberta, Canada T2N 2T9; e-mail: malmekhlafi@kau.edu.sa

Indicates article with supplemental on-line tables.

Evidence-Based Medicine Level 1.

http://dx.doi.org/10.3174/ajnr.A3682 formed in Canada in 2005. ${ }^{3}$ Stroke is an uncommon but feared complication of carotid revascularization. ${ }^{4}$ Stroke is more common after CAS, and though most of these periprocedural strokes are clinically minor, they contribute to the cumulative disability associated with the procedure. ${ }^{5}$ The largest randomized trial comparing CAS versus CEA (the Carotid Revascularization Endarterectomy versus Stenting Trial [CREST]) concluded that the outcomes after CEA versus CAS were similar because a higher risk of myocardial infarction (MI) after CEA was balanced by a higher risk of stroke after CAS. $^{2}$

Increased costs of CAS due to the costs of devices and the higher costs of stroke as a complication may be balanced by a slightly longer length of stay after CEA. ${ }^{6-9}$ These outcomes have different impacts on the patient's quality of life. ${ }^{10,11}$ We sought to determine the cost-utility of CAS compared with CEA in symptomatic patients and to understand what circumstances make CAS a cost-effective procedure. 


\section{MATERIALS AND METHODS}

The cost per quality-adjusted life years (QALY) gained with CAS compared with CEA in the treatment of patients with symptomatic carotid stenosis was assessed. The perspective of the Canadian health care system payer was adopted. The costs and clinical outcomes were modeled by using a Markov process. A lifetime time horizon was used ${ }^{12}$ to capture all relevant costs and benefits.

\section{Model}

Figure 1 presents the model structure. Given the higher risk of adverse outcomes in the initial 30 days after CAS or CEA, the first 30-day outcomes were modeled separately from long-term outcomes. Patients who survive the initial period will be in 1 of 4 health states: healthy, major stroke, minor stroke, or MI. The costs and clinical outcomes were assessed at 1-year intervals.

All clinical outcomes were taken from published randomized trials comparing CEA and CAS. Major stroke was defined as stroke that results in disability interfering with independent living. Minor stroke was defined as stroke that causes no disability or causes a disability that does not interfere with independent living. ${ }^{13}$ Myocardial infarction was defined as chest pain associated with electrocardiographic changes or elevated cardiac enzymes. The healthy state described individuals who did not have stroke or MI or die following the carotid revascularization procedure. The healthy state included patients who might have had known transient complications not typically affecting a durable quality of life, such as cranial nerve palsy following CEA or groin hematoma following CAS.

The base case analysis simulated a cohort of patients at an average age of 65 years with symptomatic carotid stenosis eligible for revascularization with either CAS or CEA. All costs and utili-

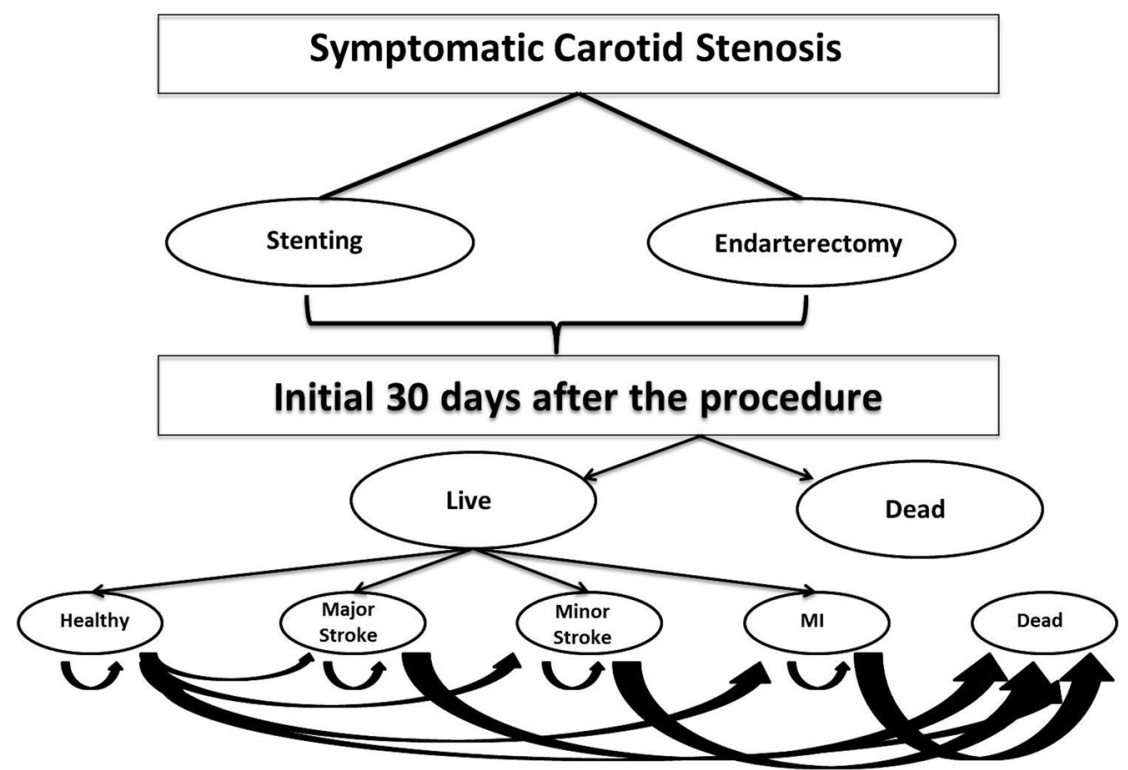

FIG 1. The Markov model structure. ties were discounted at 5\% annually. Costs were inflated to 2012 costs by using the Canadian Consumer Price Index for health and personal care. ${ }^{14}$ Decision analysis software (TreeAge Software, Williamstown, Massachusetts) was used to construct a Markov model. The study was approved by the Conjoint Health Research Ethics Board at the University of Calgary.

\section{Clinical Data}

The estimates of the clinical outcomes in the periprocedural (30day) period were pooled from the results of a recent meta-analysis, ${ }^{4}$ which included 12 major carotid revascularization trials enrolling 6973 patients (Table 1). This meta-analysis did not separately report the rates of periprocedural major and minor strokes. Data from this recent meta-analysis were reanalyzed to provide estimates of periprocedural major and minor strokes. ${ }^{4}$ The long-term clinical outcomes in those who survived the periprocedural period reported in included studies by Yavin et $\mathrm{al}^{4}$ were pooled to estimate the annual incidence of major stroke, minor stroke, and death, excluding the first 30 days. The annual risk of each outcome was calculated by dividing the total number of patients with the outcome by the number of follow-up years (excluding outcomes occurring in the first 30 days).

The risk of MI beyond the first 30 days was not reported in major randomized trials of CAS versus CEA and therefore was assumed similar among patients undergoing either procedure. Survival data beyond the follow-up of the clinical trials ( $\leq 4$ years of follow-up) were based on the study by Caro et al. ${ }^{15}$

\section{Cost Data}

Procedural Costs. Using microcosting data from the Calgary Health Zone, we selected a cohort of consecutive patients with carotid stenosis who underwent carotid revascularization (2005-2007). Costs estimates reflected the direct costs incurred by the health system. Inpatient costing data include those for investigations and treatments. Investigation costs included laboratory, imaging, and cardiac investigations. Treatment costs included the operating room and angiography suite costs; nursing care; and medications, devices, and materials used. Human resources costs (including nurses, therapists, and social workers) were also captured. Physician claims for endarterectomy, stent placement, and anesthesia were obtained from the Alberta Ministry of Health schedule of medical benefits. Hospitalization costs were cal-

Table 1: Clinical estimates for the periprocedural and annual outcomes

\begin{tabular}{|c|c|c|c|c|c|}
\hline Outcome & $\begin{array}{c}\text { Periprocedural Risk }\left(\mathrm{Cl}_{95}\right) \\
\text { after CEA }\end{array}$ & $\begin{array}{c}\text { Annual Risk }\left(\mathrm{Cl}_{95}\right) \\
\text { after } \mathrm{CEA}\end{array}$ & $\begin{array}{l}\text { Periprocedural OR }\left(\mathrm{Cl}_{95}\right) \\
\text { of CAS vs CEA }\end{array}$ & $\begin{array}{l}\text { Annual OR }\left(\mathrm{Cl}_{95}\right) \text { of } \\
\text { CAS vs CEA }\end{array}$ & References \\
\hline Death & $0.009(0.008-0.01)$ & $0.018(0.016-0.02)$ & $1.11(0.82-1.40)$ & $1.02(0.94-1.10)$ & $2,4,21,22,27,28$ \\
\hline Major stroke & $0.006(0.005-0.008)$ & $0.013(0.012-0.015)$ & $1.645(0.89-2.1)$ & $1.1(0.58-2.10)$ & \\
\hline Minor stroke & $0.022(0.019-0.025)$ & $0.0515(0.05-0.052)$ & 1.91 (1.17-3.11) & $1.3(0.75-2.08)$ & \\
\hline MI & $0.018(0.015-0.02)$ & $\mathrm{N} / \mathrm{A}$ & $0.47(0.38-0.56)$ & $\mathrm{N} / \mathrm{A}$ & \\
\hline
\end{tabular}

Note:- $\mathrm{Cl}_{95}$ indicates $95 \%$ confidence interval; N/A, not available. 
Table 2: Cost estimates (2012)

\begin{tabular}{lcc}
\hline & $\begin{array}{c}\text { Base Case Cost } \\
\text { Estimates (CDN\$) }\end{array}$ & \multicolumn{1}{c}{ Reference } \\
\hline CAS procedure & 7303 & Calgary cohort \\
CAS hospitalization & 2243 & \\
CEA procedure & 4483 & \\
CEA hospitalization & 3703 & \\
Major stroke & & \\
$\quad$ lst year & 83164 & BURST study \\
$\quad$ Annually after 1st year & 31267 & \\
Minor stroke & & \\
$\quad$ 1st year & 31136 & BURST study \\
$\quad$ Annually after 1st year & 13488 & \\
MI & & \\
$\quad$ 1st year & 4937 & Conly et al ${ }^{18}$ \\
$\quad$ Annually after 1st year & 1455 & \\
Doppler US & 237 & Government of Alberta \\
Clopidogrel (daily) & 1.18 & Government of Alberta \\
\hline
\end{tabular}

Note:-CDN\$ indicates cost estimates; US, ultrasound.

Table 3: Utility estimates

\begin{tabular}{lcl}
\hline & $\begin{array}{c}\text { Base Case Utility } \\
\text { Estimate }\end{array}$ & \multicolumn{1}{c}{ Reference } \\
\hline Baseline & 0.86 & Beaver Dam study $^{19}$ \\
Healthy & 0.86 & \\
Ml & 0.74 & SAPPHIRE $^{11}$ \\
Major stroke & 0.28 & Tengs and Linn meta-analysis $^{20}$ \\
Minor stroke & 0.64 & \\
Death & 0 & \\
\hline
\end{tabular}

culated from the asymptomatic patients and those presenting with TIAs. This calculation was performed to avoid doublecounting the rehabilitation costs associated with patients presenting with minor or major strokes. Outpatient follow-up costs were assumed similar among patients with uncomplicated carotid revascularization.

Ongoing Costs of Care. The direct costs for hospitalization and readmissions for patients having minor and major strokes were based on the findings of the multicenter Canadian Burden of Ischemic Stroke (BURST) study. ${ }^{16}$ For the base case analysis, only direct costs for patients with major and minor strokes were used (Table 2). These included costs for hospitalizations, rehabilitation, diagnostic imaging, medications, physician services, home care, changes of residence, and paid caregivers. The costs for hospitalization of patients who had MI were based on the Alberta Provincial Project for Outcome Assessment in Coronary Heart Disease data base. $^{17,18}$

\section{Utilities}

Utility scores were quoted from the published literature (Table 3). The Stenting and Angioplasty with Protection in Patients at High Risk for Endarterectomy (SAPPHIRE) trial used the baseline utilities reported by the Beaver Dam Health Outcomes Study utility score for "healthy" patients with hypertension. For the baseline utility, we used an average utility score (0.86) of those reported by the Beaver Dam Health Outcomes Study for subjects with-versuswithout hypertension in the age group corresponding to the base case analysis. ${ }^{19}$ The utility scores of major and minor strokes were based on the results of a meta-analysis. ${ }^{20}$ The utility score for MI was derived from the SAPPHIRE trial.
Table 4: Clinical characteristics of the local treatment cohorts

\begin{tabular}{lcc}
\hline & $\begin{array}{c}\text { Carotid Stenting } \\
(\boldsymbol{n}=134)\end{array}$ & $\begin{array}{c}\text { Carotid } \\
\text { Endarterectomy } \\
(\boldsymbol{n}=66)\end{array}$ \\
\hline Mean age (yr) (SD) & $72.2(8.5)$ & $69(8.8)$ \\
Women & $28.4(38 / 134)$ & $22.7(15 / 66)$ \\
Risk factors & & \\
$\quad$ Coronary artery disease & $45.5(61 / 134)$ & $18.2(12 / 66)$ \\
$\quad$ Diabetes & $30.6(40 / 134)$ & $43.9(29 / 66)$ \\
$\quad$ Hypertension & $88.1(118 / 134)$ & $68.2(45 / 66)$ \\
$\quad$ Current smoking & $32.1(43 / 134)$ & $31.8(21 / 66)$ \\
Qualifying event & & \\
$\quad$ Retinal events & $18.7(25 / 134)$ & $16.7(11 / 66)$ \\
TIA & $32.7(44 / 134)$ & $39.4(26 / 66)$ \\
Stroke & $29.9(40 / 134)$ & $25.7(17 / 66)$ \\
$\quad$ Asymptomatic & $18.7(25 / 134)$ & $18.2(12 / 66)$ \\
\hline
\end{tabular}

\section{Sensitivity Analyses}

To address the model assumptions and uncertainties, we performed multiple 1-way sensitivity and scenario analyses over plausible ranges based on the confidence intervals of clinical outcome measures, costs, utility scores, and discount rates.

Given that cost-utility estimates may vary by health care setting, we explored the impact of high surgical risk and high procedural risk outcomes by using risk estimates from major carotid revascularization trials (CREST, ${ }^{2}$ Endarterectomy versus Angioplasty in Patients with Symptomatic Severe Carotid Stenosis [EVA-3S], ${ }^{21}$ and SAPPHIRE ${ }^{22}$ ) obtained in different populations.

\section{Monte Carlo Simulation}

A Monte Carlo simulation by using a hypothetic cohort of 10,000 patients was performed to investigate the overall uncertainty in the model. Normal distributions were used for the risks, costs, and utility estimates.

\section{RESULTS}

\section{Model Validation}

The baseline characteristics of the costing cohorts for CAS and CEA are summarized in Table 4 . The cost of a CAS procedure was estimated at $\$ 7303$, while the hospitalization cost was $\$ 2240$. Compared with CAS, the cost of a CEA procedure was lower at $\$ 4483$ but had a higher hospitalization cost of $\$ 3703$. The decision model structure, estimates, and assumptions were reviewed by experts in the field of cerebrovascular diseases (M.D.H., J.H.W.) and health economics (F.M.C.). The internal validity of the model was verified by comparison of predicted outcomes and input clinical risks. External validity was evaluated by comparing the predicted clinical outcomes with observed clinical outcomes at 4 years from the major clinical trials (On-line Table 1). Our predicted probabilities matched the observed probabilities within $20 \%$.

\section{Base Case Cost-Utility Analysis}

In the base case analysis, CAS was more expensive than CEA (incremental cost of \$6107) and had a lower effectiveness ( -0.12 QALYs); CAS was dominated by CEA. (Table 5).

\section{One-Way Sensitivity Analyses}

The model results were not affected by varying the discount rate or periprocedural or annual risk of major or minor stroke 
Table 5: Base case and scenario analyses

\begin{tabular}{|c|c|c|c|c|c|c|}
\hline Strategy & Cost & $\begin{array}{c}\text { Incremental } \\
\text { Cost (\$) }\end{array}$ & $\begin{array}{l}\text { Effectiveness } \\
\text { (QALYs) }\end{array}$ & $\begin{array}{l}\text { Incremental } \\
\text { Effectiveness }\end{array}$ & $\begin{array}{c}\text { Incremental } \\
\text { Cost-Effectiveness }\end{array}$ & ICER \\
\hline \multicolumn{7}{|l|}{ Base case } \\
\hline CEA & $\$ 24,624$ & & 6.83 & & 3605 & \\
\hline CAS & $\$ 30,731$ & $\$ 6107.00$ & 6.71 & -0.12 & 4580 & Dominated $^{a}$ \\
\hline \multicolumn{7}{|l|}{ SAPPHIRE } \\
\hline CEA & $\$ 77,377$ & $\$ 14,801.48$ & 5.14 & -1.96 & 15049 & Dominated $^{a}$ \\
\hline CAS & $\$ 62,576$ & & 7.1 & & 8814 & \\
\hline \multicolumn{7}{|l|}{ EVA-3S } \\
\hline CEA & $\$ 22585$ & & 6.82 & & $\$ 3312$ & \\
\hline CAS & $\$ 30,832$ & $\$ 8246.38$ & 6.67 & -0.15 & $\$ 4695$ & Dominated $^{a}$ \\
\hline \multicolumn{7}{|l|}{ CREST } \\
\hline CEA & $\$ 22,259$ & & 6.89 & & $\$ 3227$ & \\
\hline CAS & $\$ 25,846$ & $\$ 3587.00$ & 6.63 & -0.27 & $\$ 3900$ & Dominated $^{a}$ \\
\hline
\end{tabular}

Note:-ICER indicates incremental cost-effectiveness ratio.

a "Dominated" means that the treatment modality was associated with more cost and less effectiveness.

ICE Scatterplot of

CAS vs. CEA

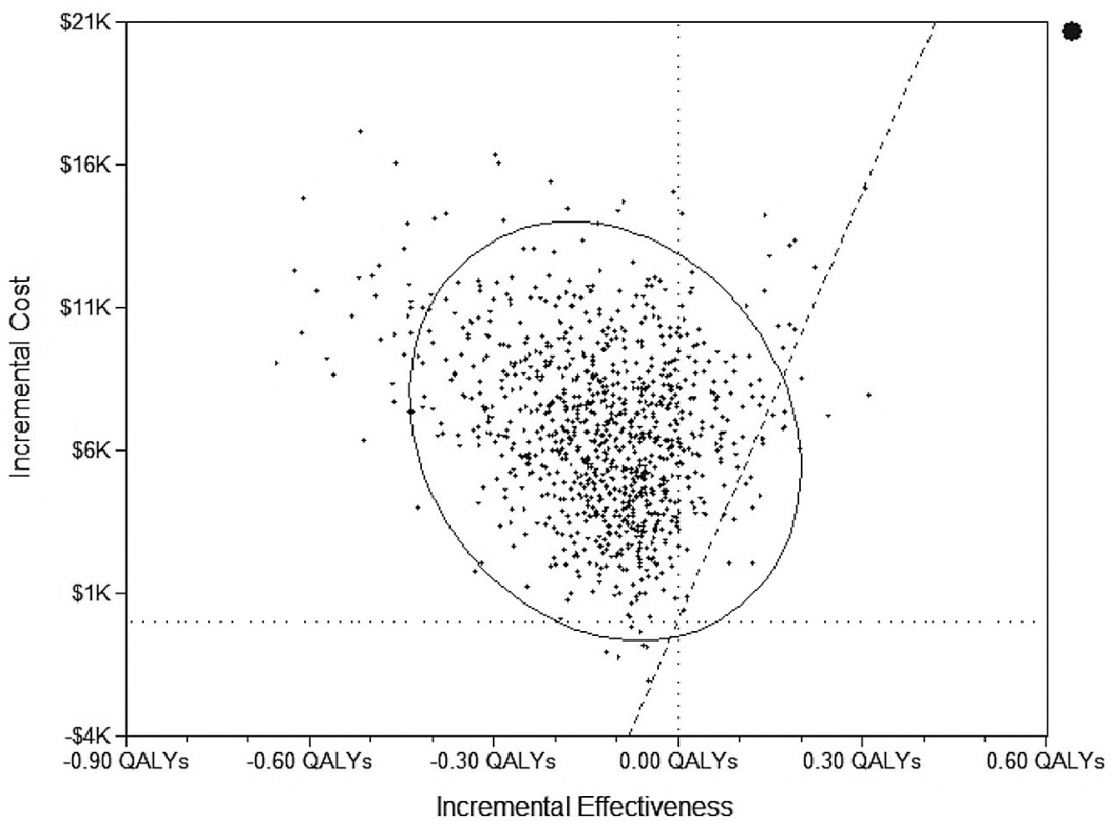

FIG 2. Scatterplot of the cost-effectiveness plane.

(On-line Table 2). The cost of MI did not impact the results. The procedural cost of CAS did not influence these results even when costs as low as $\$ 1000$ per procedure were used.

The model results were sensitive to variation in the annual mortality risk. When CAS was associated with a lower risk of death compared with CEA, at a threshold relative risk of 0.85 , CAS was associated with an incremental cost-effectiveness ratio of $\$ 32,839$ per QALY gained compared with CEA.

\section{Scenario Analyses Based on Major Trials}

When estimates from trials of high-procedure-risk populations (EVA-3S) or of patients treated with the North American standards (CREST trial) were used (On-line Table 3 ), the results were unchanged. With estimates from the high surgical risk population (SAPPHIRE trial), CAS was cost-effective relative to CEA (Table 5). The higher risk of death and major strokes associated with CEA described in that trial led to higher costs and reduced QALYs.

\section{Threshold Analyses}

Only after simultaneously reducing CAS procedural costs from $\$ 7300$ to $\$ 4350$, the relative risks of minor periprocedural strokes (relative risk $=1.0$ ), and the annual relative risk of stroke (relative risk $=$ 1.15) does CAS become the preferred option.

In the Monte Carlo simulation, the estimated net costs in the simulated cohort were $\$ 28,615$ (95\% CI, \$28,556$\$ 28,674)$ for CAS and $\$ 22,948$ (95\% CI, $\$ 22,919-\$ 22,976)$ for CEA. Almost all simulations fell in the upper quadrants, indicating the presence of incremental costs associated with CAS in most simulations (Fig 2). However, the scatter across the horizontal plane indicates uncertainty in the effectiveness of CAS versus CEA.

\section{DISCUSSION}

Overall, CAS was associated with higher costs and lower effectiveness compared with CEA among patients with symptomatic carotid stenosis. These results were driven by the costs of both the procedure and the associated periprocedural adverse outcomes (primarily major and minor stroke). The costs associated with MI did not impact the results. These results were sensitive to annual survival following the procedure. Longer survival is associated with greater cost-effectiveness for CAS. ${ }^{23}$

CAS was cost-effective under certain circumstances. Among patients with high-surgical-risk features, CAS was associated with both lower costs and higher QALY gains. This was largely influenced by the lower risk of major and minor periprocedural stroke associated with CAS. While careful patient selection is an important factor in reducing procedural complications, the risk of periprocedural stroke remains higher with CAS across many major trials. If and when the safety of CAS is improved through the development of the technology and procedural innovation, CAS may become cost-effective relative to CEA.

Monte Carlo simulated cohort analysis showed some uncertainty around the effectiveness of CAS compared with CEA, but costs were always higher with CAS. Distal protection devices, balloons, stents, and guiding catheters used for CAS are expensive, collectively approaching $\$ 4500$. These costs outweigh any savings associated with shorter hospitalization after CAS. Therefore, improving CAS safety is an alternative approach to improving its cost-effectiveness.

There are multiple steps involved in performing CAS; some of these are the subject of ongoing debate because of safety concerns. For example, the use of distal protection devices and poststent 
balloon angioplasty are 2 procedural steps that are not universally performed. While angioplasty balloons cost approximately $\$ 300$ per device, the cost of the distal protection device is $\$ 1900 .{ }^{24}$ Identifying the safety of these instruments is important to enable the assessment of the potential clinical and economic impact of eliminating such steps that might be hazardous.

These results are concordant with reports from other jurisdictions. ${ }^{10,11,25,26}$ The higher procedural cost associated with CAS was unanimously reported by these studies, and the cost of stroke care was a major driver of the cost-utility analyses. The cost estimates used in this analysis for patients with major and minor stroke were significantly higher compared with other reports. The BURST trial estimates included costs for postdischarge care, which were not reported in many other trials and provide a novel Canadian context.

This study has limitations. The analysis was based on clinical estimates from a meta-analysis that combined patients with variable clinical characteristics treated via different protocols. While the effects of this variability were examined by performing multiple sensitivity and scenario analyses, the base case results should be interpreted bearing in mind the limitations of available evidence. Moreover, the model provides outcomes and costing data beyond what is known from these trials. The analysis adopts a public health system perspective, and indirect costs were not included in this analysis. Therefore, the reported costs represent an underestimate of the actual total costs associated with both procedures. Some adverse outcomes occasionally seen with CEA, such as cranial nerve injuries, which are rarely disabling, were not considered in this analysis. Despite these limitations, this analysis not only provides an assessment of the cost-utility of CAS in the Canadian health system but it also explored factors influencing these costs and suggests potential saving strategies.

\section{CONCLUSIONS}

Overall, CEA was the cost-effective procedure relative to CAS for patients with symptomatic carotid stenosis. CAS provides an attractive incremental cost-effectiveness ratio in the high-surgical-risk population. Effort should be focused on reducing the periprocedural stroke risk and procedural costs to improve CAS cost-effectiveness.

Disclosures: Michael D. Hill—RELATED: Other: site for the Carotid Revascularization Endarterectomy vs. Stenting Trial (CREST) study (local site principal investigator), ${ }^{*}$ Comments: money from National Institutes of Health grant to pay for per-patient costs for the CREST study, UNRELATED: Board Membership: Heart and Stroke Foundation Alberta, Northwest Territories, Nunavut, Comments: provincial advisory board, no remuneration, volunteer work, Payment for Lectures (including service on Speakers Bureaus): Sanofi Canada, Bristol-Meyers Squibb Canada, Comments: honoraria for lecturing at continuing medical education events, Stock/Stock Options: Calgary Scientific Inc, Comments: stockholder in this company (an image-processing company). Samuel Wiebe-UNRELATED: Travel/Accommodations/Meeting Expenses Unrelated to Activities Listed: International League against Epilepsy, Comments: executive board member. Mayank Goyal—UNRELATED: Consultancy: Covidien/ev3, Comments: for speaking engagement, trial design, and so forth, Grants/ Grants Pending: Covidien/ev3,* Comments: partial funding of the ESCAPE (Endovascular treatment for Small Core and Anterior circulation Proximal occlusion with mphasis on minimizing CT to recanalization times) trial, Payment for Lectures (including service on Speakers Bureaus): Covidien/ev3, Comments: for lectures related to acute stroke treatment, Stock/Stock Options: NoNO Inc, Calgary Scientific Inc. *Money paid to the institution.

\section{REFERENCES}

1. Rothwell PM, Eliasziw M, Gutnikov SA, et al. Analysis of pooled data from the randomised controlled trials of endarterectomy for symptomatic carotid stenosis. Lancet 2003;361:107-16

2. Brott TG, Hobson RW 2nd, Howard G, et al. Stenting versus endarterectomy for treatment of carotid-artery stenosis. $N \mathrm{Engl} \mathrm{J} \mathrm{Med}$ 2010;363:11-23

3. Dai S, Bancej C, Bienek A, et al. Tracking heart disease and stroke in Canada 2009. Chronic Diseases in Canada Ottawa, Ontario: Public Health Agency of Canada 2009;29:192-93

4. Yavin D, Roberts DJ, Tso M, et al. Carotid endarterectomy versus stenting: a meta-analysis of randomized trials. Can J Neurol Sci 2011;38:230-35

5. Blackshear JL, Cutlip DE, Roubin GS, et al. Myocardial infarction after carotid stenting and endarterectomy: results from the carotid revascularization endarterectomy versus stenting trial. Circulation 2011;123:2571-78

6. Jordan WD Jr, Roye GD, Fisher WS 3rd, et al. A cost comparison of balloon angioplasty and stenting versus endarterectomy for the treatment of carotid artery stenosis. J Vasc Surg 1998;27:16-22, discussion 22-14

7. Kilaru S, Korn P, Kasirajan K, et al. Is carotid angioplasty and stenting more cost effective than carotid endarterectomy? J Vasc Surg 2003;37:331-39

8. Ecker RD, Brown R Jr, Nichols DA, et al. Cost of treating high-risk symptomatic carotid artery stenosis: stent insertion and angioplasty compared with endarterectomy. J Neurosurg 2004;101:904-07

9. Park B, Mavanur A, Dahn M, et al. Clinical outcomes and cost comparison of carotid artery angioplasty with stenting versus carotid endarterectomy. J Vasc Surg 2006;44:270-76

10. Vilain KR, Magnuson EA, Li H, et al. Costs and cost-effectiveness of carotid stenting versus endarterectomy for patients at standard surgical risk: results from the Carotid Revascularization Endarterectomy Versus Stenting Trial (CREST). Stroke 2012; 43:2408-16

11. Mahoney EM, Greenberg D, Lavelle TA, et al. Costs and cost-effectiveness of carotid stenting versus endarterectomy for patients at increased surgical risk: results from the SAPPHIRE trial. Catheter Cardiovasc Interv 2011;77:463-72

12. Guidelines for the Economic Evaluation of Health Technologies. 3rd ed. Ottawa, Ontario, Canada: Canadian Agency for Drugs and Technologies in Health; 2006

13. Kwon S, Hartzema AG, Duncan PW, et al. Disability measures in stroke: relationship among the Barthel Index, the Functional Independence Measure, and the Modified Rankin Scale. Stroke 2004;35:918-23

14. Consumer Price Index, health and personal care, by province (monthly). Statistics Canada. http://www.statcan.gc.ca/tablestableaux/sum-som/101/cst01/cpis13a-eng.htm. Accessed January 2012

15. Caro JJ, Ishak KJ, Migliaccio-Walle K. Estimating survival for costeffectiveness analyses: a case study in atherothrombosis. Value Health 2004;7:627-35

16. Mittmann N, Seung SJ, Hill MD, et al. Impact of disability status on ischemic stroke costs in Canada in the first year. Can J Neurol Sci 2012;39:793-800

17. Ghali WA, Knudtson ML. Overview of the Alberta Provincial Project for Outcome Assessment in Coronary Heart Disease: on behalf of the APPROACH investigators. Can J Cardiol 2000;16:1225-30

18. Conly J, Clement F, Tonelli M, et al. Cost-effectiveness of the use of low- and high-potency statins in people at low cardiovascular risk. CMAJ 2011;183:E1180-88

19. Fryback DG, Dasbach EJ, Klein R, et al. The Beaver Dam Health Outcomes Study: initial catalog of health-state quality factors. Med Decis Making 1993;13:89-102

20. Tengs TO, Lin TH. A meta-analysis of quality-of-life estimates for stroke. Pharmacoeconomics 2003;21:191-200

21. Mas JL, Trinquart L, Leys D, et al. Endarterectomy Versus Angioplasty in Patients with Symptomatic Severe Carotid Stenosis (EVA- 
3S) trial: results up to 4 years from a randomised, multicentre trial. Lancet Neurol 2008;7:885-92

22. Gurm HS, Yadav JS, Fayad P, et al. Long-term results of carotid stenting versus endarterectomy in high-risk patients. $N$ Engl J Med 2008;358:1572-79

23. Hobson RW 2nd, Howard VJ, Roubin GS, et al. Carotid artery stenting is associated with increased complications in octogenarians: 30day stroke and death rates in the CREST lead-in phase. J Vasc Surg 2004;40:1106-11

24. Jacobs P, Fassbender K. The measurement of indirect costs in the health economics evaluation literature: a review. Int J Technol Assess Health Care 1998;14:799-808

25. Janssen MP, de Borst GJ, Mali WP, et al. Carotid stenting versus carotid endarterectomy: evidence basis and cost implications. Eur J Vasc Endovasc Surg 2008;36:258-64, discussion 265-66
26. Maud A, Vazquez G, Nyman JA, et al. Cost-effectiveness analysis of protected carotid artery stent placement versus endarterectomy in high-risk patients. J Endovasc Ther 2010;17:224-29

27. Brooks WH, McClure RR, Jones MR, et al. Carotid angioplasty and stenting versus carotid endarterectomy: randomized trial in a community hospital. J Am Coll Cardiol 2001;38: 1589-95

28. Steinbauer MG, Pfister K, Greindl M, et al. Alert for increased long-term follow-up after carotid artery stenting: results of a prospective, randomized, single-center trial of carotid artery stenting vs carotid endarterectomy. J Vasc Surg 2008;48: 93-98

29. Seung S, Mittmann N, Sharma M, et al. The methodology behind a prospective, observational study of the economic burden of ischemic stroke. Value Health 2005;8:A153 